\title{
Evaluating Needle Sticks and Sharp Object Injuries in a Developing Country: A Diagnostic Institute in Dominican Republic
}

\author{
Michelle P. Taveras ${ }^{1}$ and Paul Barach ${ }^{2}$ \\ ${ }^{1}$ University of Miami, Miller School of Medicine, Miami, USA \\ ${ }^{2}$ Center for Patient Safety, Utrecht University Medical Center, Utrecht, The Netherlands
}

doi: 10.3396/ijic.V6i2.017.10

\begin{abstract}
The goal of the study is to review the impact of sharp object injuries to healthcare professionals in a developing country in order to prevent them. A cross-sectional survey was conducted in an advanced diagnostic and imaging hospital. Out of 350 healthcare workers, 100 were randomly enrolled in the study and did not use any restrictions in randomization. Incomplete surveys were discarded. 71 surveys were considered for this study. The survey consisted of 9 questions focusing on sharp object injuries. The questionnaire was intended to identify which group of healthcare workers had the highest risk of exposure and what types of sharp objects they were being exposed to. Interviews were also conducted. It was piloted with laboratory technicians. During the pilot, no changes were made to the questionnaire. Of those surveyed $(n=71), 21 \%$ reported exposure to sharp object injuries over their period of employment at the diagnostic institute. Needle stick injuries were the most common type of injury. Laboratory technician was the job category with the most reported exposures. There is a $29 \%$ probability that a staff member will come in contact with an infectious disease every year through sharp object injuries. Recommendations to decrease sharps exposure include creating a computerized reporting process called Sharps Injury Reporting Process, building an infectious disease committee, implementing safety instrumentation while addressing the issue of cost, surveying staff every 6 months, and increasing administration involvement.
\end{abstract}

\section{Key Words}

infection control, developing countries, sharp object injuries, blood-borne pathogens, patient safety

\section{Corresponding author}

Michelle P. Taveras, University of Miami, Miller School of Medicine, Miami, FL 33136

Tel: 305-326-6043, Fax: 305-326-6318, Email: mtaveras@med.miami.edu 


\section{Background}

Contaminated sharps, such as syringes and biopsy needles, can transmit infectious diseases to healthcare workers putting at risk both staff and patients. ${ }^{1}$ In a workshop conducted by the Institute of Medicine (IOM) in 2000, titled "Public Health Systems and Emerging Infections: Assessing the Capabilities of the Public and Private Sectors", the issues of infectious disease surveillance and outbreak detection were discussed. ${ }^{2}$ This workshop laid the foundation for developing processes and methodologies for controlling bloodborne infections. Furthermore, the emergence and re-emergence of infectious diseases add a level of complexity to the control of infectious disease prevalent in developing countries. These would include Hepatitis B and C (HBV and HCV) and Human Immunodeficiency Virus (HIV). Controlling the spread of occupationally-transmitted diseases locally, nationally and globally is an area of intense research. ${ }^{3}$ This study addresses the need for additional research at the local level for facilities that have not yet established a baseline and developed corrective practices based on their own experience. regarding prevention of sharp injuries in their healthcare settings.

This study focuses on sharp injuries occurring at a diagnostic and imaging center in the Dominican Republic. The study began after reviewing the basic needs of the center. It was identified that in order to improve safety, the center had to start by ensuring the staff was taking the proper precautions to control sharps injury exposures within the institute. The need to develop a comprehensive infection control program as corner stone to a strong and safe healthcare delivery system was identified. The authors started the initiative by reviewing two proven infectious disease programs published by the Center for Disease Control and World Health Organization.

To appeal to Administration, the cost associated with sharps injury exposure to infectious diseases was calculated. It is estimated that follow up treatment of exposed personnel can range from US $\$ 3.8$ to up to US $\$ 9,603.4,5,6$ Healthcare institutes must consider the cost and benefits associated with implementing a wellrounded sharps injury reduction and infection control program.

\section{Overview: needle sticks}

With all the technological advancements, a need to heighten the focus on safety for both staff and patients has arisen. The work environment must change in order to reduce sharps exposures. The Center for Disease Control (CDC) states that about $68 \%$ of exposures are not reported. Others studies have found $96 \%$ underreporting in the OR. Another study showed that $70 \%$ of surgeons never or rarely report needle stick injuries. ${ }^{7}$ The most common reasons found were paperwork hassle, time constraints, perceived low risk of infection, workload pressure, passive surveillance of administrative personnel, and unawareness of reporting system. ${ }^{7}$ Currently, the reporting of sharp object exposure is not systematic. Other studies in developing countries have been successfully completed. In a study conducted in Taiwan by Hsieh et al., a 3 year review of exposures was conducted. They too found that needle sticks was the highest reported cause of injuries. In the United States, it is reported that 600,000 to 800,000 needle sticks occur yearly. ${ }^{8}$ Substantial under-reporting is thought to be between $30-94 \%{ }^{8}$

Additionally, it is estimated that general unsafe injection practices in low income countries translates to about 260,000 HIV exposures, 21 million HBV infections per year as of the year 2000, and 2 million HCV infections each year $9,10,11$

\section{Overview: Dominican Republic}

The Dominican Republic is located in the Caribbean and shares the island of Hispaniola with Haiti. It currently has a population of about 8.89 million people. According to the World Health Organization, its health indicators are as follows:

HIV, and hepatitis B and C are of major concerns with the occurrence of sharp object exposure in Dominican Republic.

Human immunodeficiency virus (HIV) is a retrovirus that causes acquired immune deficiency syndrome (AIDS), a condition in humans in which the immune system begins to fail, leading to life-threatening opportunistic infections. AIDS (HIV) in Dominican Republic affects $1.1 \%$ of total population or about 97,845 people. This is believed to be grossly underreported. Infection with HIV occurs by the transfer of blood, semen, vaginal 
Table I: Dominican Republic National Health Indicators

\begin{tabular}{|l|}
\hline \multicolumn{1}{|c|}{ Indicators } \\
\hline GDP per capita (Intl \$, 2004): 4,986 \\
\hline Life expectancy at birth m/f (years): 64.0/70.0 \\
\hline Healthy life expectancy at birth m/f (years, 2002): 57.2/61.9 \\
\hline Child mortality m/f (per 1000): 34/30 \\
\hline Adult mortality m/f (per 1000): $280 / 169$ \\
\hline Total health expenditure per capita (Intl \$, 2003): 335 \\
\hline Total health expenditure as \% of GDP $(2003): 7.0$ \\
\hline
\end{tabular}

fluid, Cowper's fluid or breast milk. Within these bodily fluids HIV is present as both free virus particles and virus within infected immune cells. In 2002, worldwide data confirmed that about 106 healthcare professionals contracted HIV through blood and body fluid exposure. ${ }^{12}$

Another dominant infectious disease is Hepatitis B (HBV). Other types of hepatitis, all transmissible by blood, such as A, C and D have also been occupationally transmitted. Hepatitis B can cause lifelong infection, cirrhosis (scarring) of the liver, liver cancer, liver failure, and death. ${ }^{13,14}$

In a study conducted by Mazzur et al., an analysis of Hepatitis B blood donors demonstrates the level of infection found in the Dominican Republic (DR). DR was found to have the highest level of infection among the 13 countries studied in 1980. Out of all samples, $82.8 \%$ demonstrated antibodies to hepatitis $\mathrm{B} .{ }^{15}$ In another more recent study conducted by Silveira et al. in 1997, 473 subjects were tested for HBV. $12.6 \%$ of male samples and $24 \%$ of female samples were found to be HBV positive (95\% confidence). The overall seroprevalance for antibodies for all samples was $21.4 \% .^{16}$

The facts on HIV, HBV, HCV related to Dominican Republic clearly support the purpose of this study. In this study, we assess the current healthcare workforce at the diagnostic and imaging center if the purpose of documenting the rate of sharps injuries for the different job categories.

\section{Methods}

We evaluated the clinical and administrative processes in high exposure areas with the goal of categorizing high risk procedures. Processes were diagramed using flow charts with the purpose of identifying process improvement opportunities. We then identified that the diagnostic and imaging center does not have a sharp objects exposure database, nor does it have clear policies and procedures to address sharp sticks or cuts, nor does it have an infection control program. Therefore, a study was designed and conducted with the purpose of assessing, designing, and executing a sharp exposure prevention program. ${ }^{17}$

\section{Survey Tool}

To create a baseline, a short 9 question survey was developed using recommendations from the Centers for Disease Control (CDC) and literature review. The EPInet program was also evaluated and 4 questions selected and adapted to survey design. ${ }^{18}$ These included job category, physical location of the injury, timing of when the injury occured and type of device causing injury, The survey was piloted on laboratory technicians. The only issue identified was the definition of Sharp Objects. This definition was added to the survey.

The study enrolled 100 subjects out of 350 employees chosen at random. The subjects included physicians, residents, interns, medical students, nurses, technicians, administration and housekeeping staff. Laboratories, imaging areas, and operating rooms were locations specifically surveyed for patient care role. The survey 
Table II: Survey Tool

\begin{tabular}{|c|c|}
\hline 1. What type of hospital function do you currently perform? & If yes, \\
\hline Medico/Doctor & 5. Which object? \\
\hline Medico Pasante/ Intern or Resident & Jeringuillas tradicionales/ Syringes \\
\hline Estudiante de Medicina/Medical student & Mariposa/ Butterfly \\
\hline Enfermera/ Nursing & Bisturi/ Scalpel \\
\hline Tecnico/Technician & Linea de accesso por cateter/ catheter line \\
\hline Bio-analista/ Bioanalist (lab tech) & Aquja de biopsia/Biopsy needle \\
\hline Servicio de Limpieza/ Housekeeping & Vidrio/Glass \\
\hline Administracion/ Administration & Otro/ Other \\
\hline \multicolumn{2}{|l|}{ Especialista/Specialist } \\
\hline \multirow{2}{*}{ Otro/Other } & 6. Where did it happen? \\
\hline & Sala de operacion/Operating room \\
\hline 2. Which Department do you work for? & Sala de procedimiento/Procedure Room \\
\hline Cardiologia/ Cardiology & Clinicas/Clinics \\
\hline Laboratorios/ Laboratory & Laboratorio/Laboratory \\
\hline Neurologia/ Neurology & Cuartos de pacientes internos/Inpatient rooms \\
\hline Hemodinamia/ Hemodinamist & Basura, Ropa Sucia/ Trash, Dirty Laundry \\
\hline Gastroenterelogia/Gastroenterelogy & Otro/ Other \\
\hline \multicolumn{2}{|l|}{ Medician Nuclear/ Nuclear Medicine } \\
\hline Ortopedia/ Orthopedics & 7. How did it happen? \\
\hline Imagenologia/ Radiology & Linea de accesso/ Access line \\
\hline Plan Ejecutivo de Salud/Executive Care Plan & $\begin{array}{l}\text { Pasando objeto punzante entre equipo medico/ Passing needle object } \\
\text { between medical staff }\end{array}$ \\
\hline Facilidades Hospitalarias/ Hospital & Durante la limpieza/ During housekeeping \\
\hline Urologia/Urology & Mientras se destrulle el objeto/ During the disposile of sharp \\
\hline Cirugia/Surgery & $\begin{array}{l}\text { Mientras se manipula el objeto en el paciente/While manipulating shar } \\
\text { in patient }\end{array}$ \\
\hline Neumologia/Neumology & Otro/Other \\
\hline \multicolumn{2}{|l|}{ Otro/Other } \\
\hline \multicolumn{2}{|l|}{ 3. Which types of sharp objects are you exposed to during your daily job? } \\
\hline Jeringuillas tradicionales/Syringes & 8. Sex \\
\hline Mariposa/ Vaccutanerur & Hombre/Male \\
\hline Bisturi/Scalpel & Mujer/Female \\
\hline \multicolumn{2}{|l|}{ Linea de accesso por cateter/ catheter line } \\
\hline Aquja de biopsia/Biopsy needle & 9.Age \\
\hline Vidrio/ Glass & $15-25$ yrs old \\
\hline \multirow[t]{2}{*}{ Otro/Other } & $26-35$ yrs old \\
\hline & $36-45$ yrs old \\
\hline 4. Have you had a sharp object incident while working in this hospital? & $46-55$ yrs old \\
\hline Yes & $56-65$ yrs old \\
\hline No & $65+$ yrs old \\
\hline
\end{tabular}

was anonymous and only required age and gender of the staff members completing the survey.

\section{Interviews}

Staff interviews were performed while conducting a walkthrough in the different clinical areas. The most noted observation was that when an incident occured, there was no official reporting process or policy to follow. Post exposure Prophylaxis (PEP) is not required and left up to the employee. ${ }^{6}$

While interviewing 2 inpatient nurses, they noted using processes learned in other institutions for treating sharp object exposures. The process they followed included:

1. Flush exposed area immediately after contact with water,
2. Disinfect area with an antiseptic,

3. Apply tetanus shot if necessary,

4. Check patient record to see if there is any documentation of infectious diseases,

5. Check blood for infectious disease if exposure came from handling blood sample (if blood available). No post-exposure prophylaxis was used in a consistent manner.

Laboratory (lab) employees were also interviewed. The Laboratory Director stated that gloves, disinfectants, and ability to choose the needle best for the patient are always available. The employees that work at the blood drawing stations stated that their biggest concern was a nervous patient, elderly patients, and children while using a traditional syringe. Lab analysts noted that their biggest exposure risk happened when manipulating 
the Petri dish. However, if they happened to get cut or injured, they would go ahead and test the blood for HIV, HBV, HBC, and Syphilis. No consent from patients is obtained prior to conducting these tests. No clear post exposure prophylaxis plan was noted by any of the staff interviewed.

The laboratory director stated that the institute did not have a centralized location for dealing with sharps injury assessment process, such as an Employee Health Office. Each department basically dealt with it internally.

A three-day walk thru in areas such as laboratory, radiology, and inpatient units, as well as interviews with the staff, provided observations on the types of sharps used, sharp disposal, and application of engineering solutions to reduce sharps injuries. Figures 1, 2, and 3 are examples of sharps used by staff members in the different areas. Pictures of scalpels are not available.

Figure 4 shows the use of sharp object disposal containers. One of the questions in the survey addresses the disposal of sharps as it relates to injuries. It was

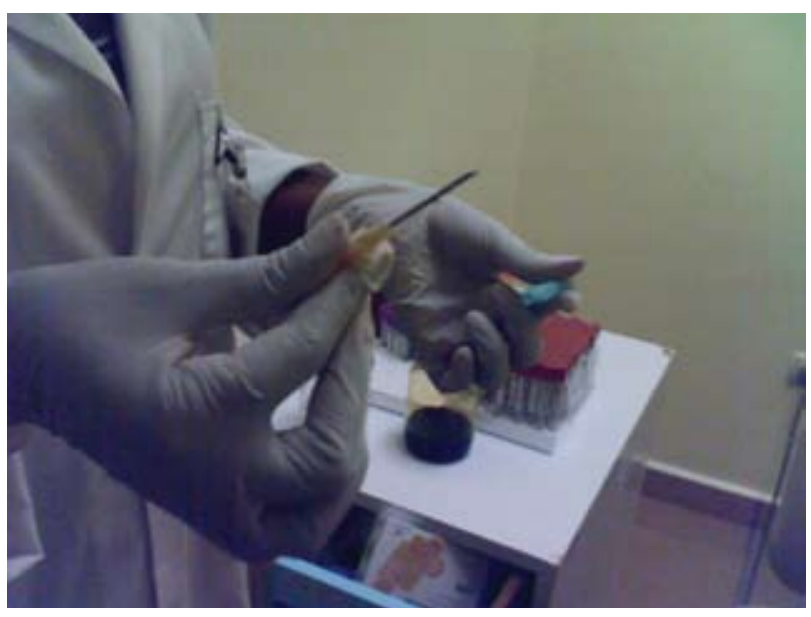

Figure 1. Blood Bank needles

observed that in some areas there were plastic sharps containers, others had metal sharps containers, and in others red bags in plastic containers were used for disposal of soiled materials and sharps. The red color is what indicates to housekeeping that the material should be incinerated because it is bio-hazardous. Metal containers were mostly found in procedural and imaging areas. Red bags were found in inpatient rooms, procedural and imaging areas. Red bags were

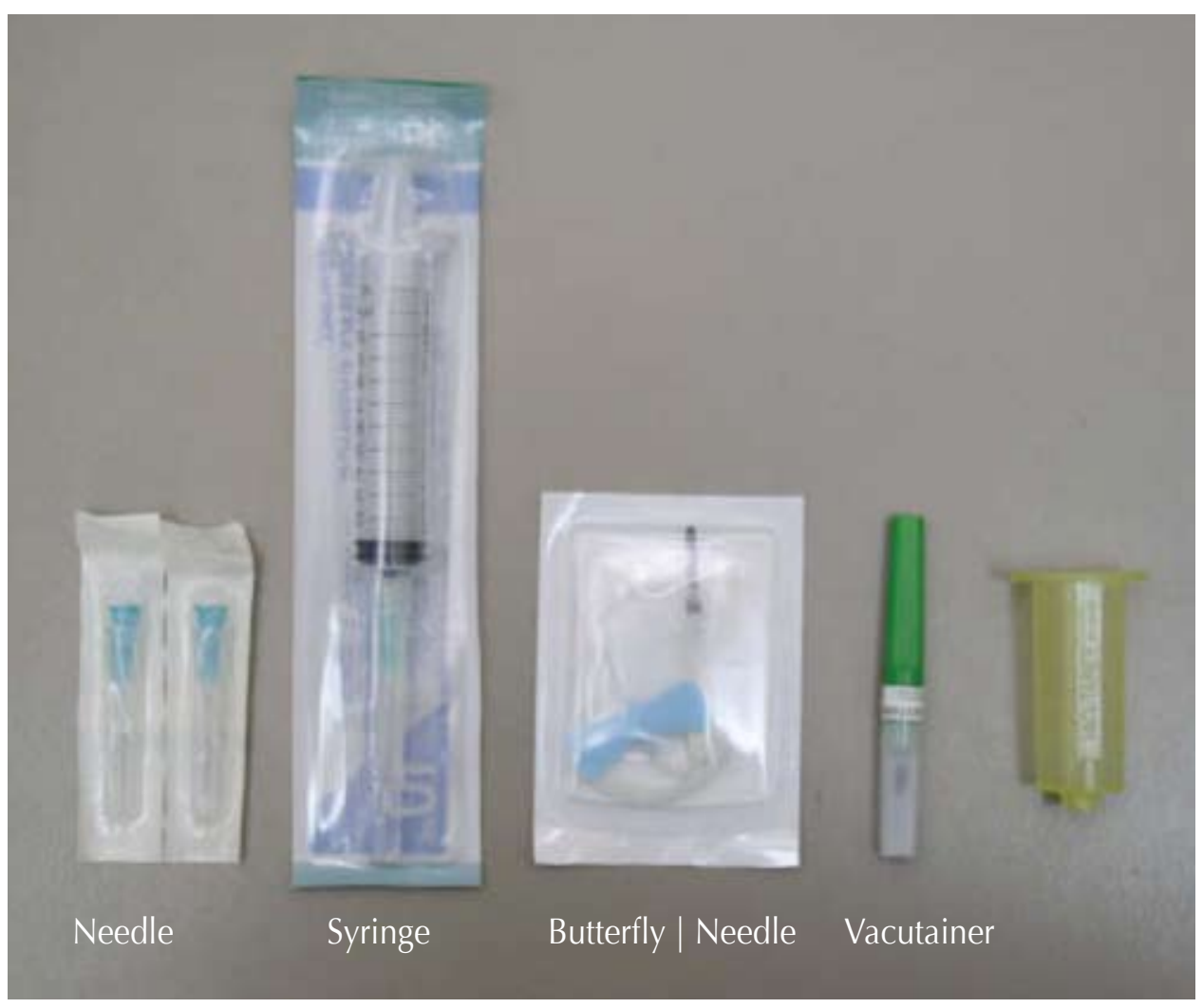

Figure 2. Blood drawing and injection sharps 

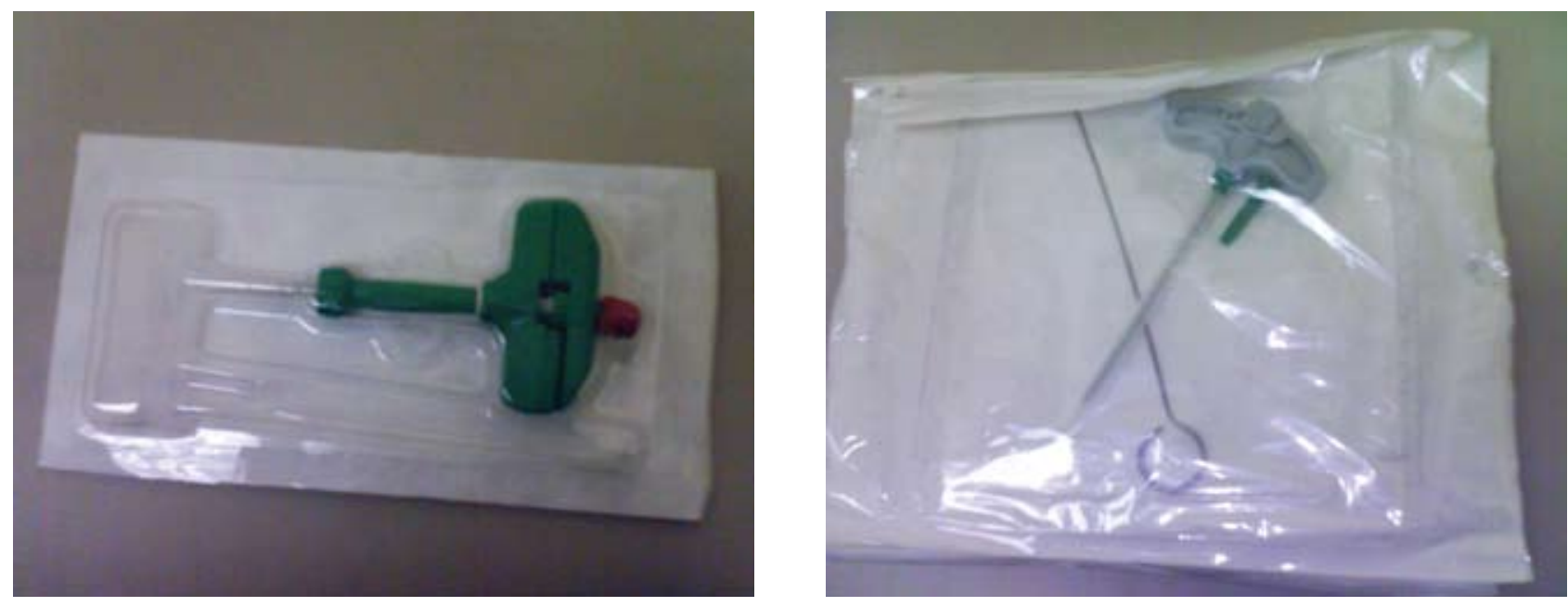

Figure 3. Biopsy needles

not always available and black bags were sometimes used for the same purpose. This failure to place the correct colored bag could be a breach in safety. The study did not measure the occurrence or lack of available safe sharps disposal containers.

It was noted that suggestions such as double gloving are not popular. ${ }^{19}$ However, engineered solutions such as vacutainer and scalpels with handles are sometimes used. In areas such as Operating Rooms, biopsy units, laboratories, and inpatient unit, it was noted that engineered solutions are not always used because of cost. For example, a vacutainer needle costs around US $\$ 1$ while a syringe costs around US $\$ 0.20$.

\section{Results}

The three largest sampling groups included 15 physicians (22\%), 17 laboratory technicians $(25 \%)$, and 20 housekeeping staff members (30\%). 21\% of the staff members enrolled in the study have been exposed to sharp object injury. If the housekeeping staff was removed from the sample, $26 \%$ of clinical staff has been exposed to sharp object injury during their length of employment with the institute. The most common type of injury was caused by the traditional syringe $(45 \%) .46 \%$ of surveyed personnel stated that the injury occurred in a laboratory, including genetics lab, blood bank lab, etc.

The sampling distribution included $36 \%$ men and $64 \%$ female. This sample is representative of current

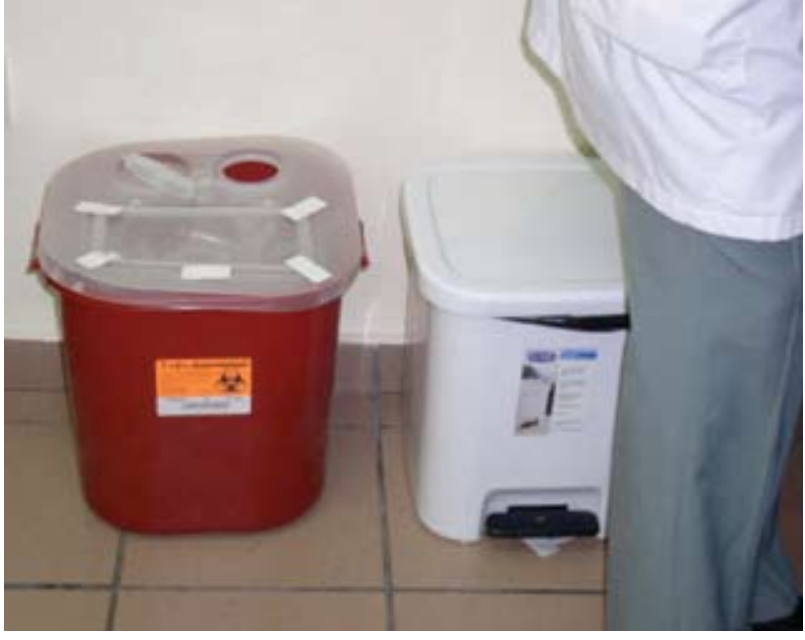

Figure 4. Sharp Disposal

healthcare gender trends which further supports the sampling plan. The figure also shows the age distribution of those sampled. The largest sample at $41 \%$ is of staff between the ages of 35 and 46 years old. The second largest sample at 33\% includes those between the ages of 25 to 34 years old.

The type of job function was surveyed. The focus of the survey was to sample clinical and Housekeeping staff. A low occurrence of sharp object injury implies proper disposal of sharps, and could also indicate low exposure rate. The 4 largest groups interviewed were housekeeping with 20 observations (30\%), laboratory technicians with 17 observations (22\%), physicians 
with 15 observations (22\%), and nursing with 10 observations (15\%).

Fourteen departments/areas at the institute were surveyed. For future surveys, covering those departments excluded from this study would be ideal. Laboratories $(37 \%)$, which include genetics, blood bank, blood drawing stations, blood analyzing stations, microbiology, and Executive Care Plan (29\%), which crosses over all departments, were the most sampled. There were 24 observations in the laboratories and the 19 observations in the Executive Care Plan.

The survey also contained questions on the nature of exposure the staff had to different types of sharps. The highest exposure is to traditional syringes (27\%). Biopsy needles $(18 \%)$ and scalpels $(17 \%)$ were also commonly associated with injuries among the staff.

The purpose of the survey is to quantify the exposure of staff members to sharp objects. Of all surveyed, 21\% of people surveyed said they had had some type of sharp object exposure while working at the diagnostic and imaging center. $45 \%$ of those exposures occurred with traditional syringes. $23 \%$ of the sharp object injuries were with a butterfly. The highest incidence rate for location exposure were the laboratory and the operating room. $46 \%$ during laboratory work, 20\% indicated it happened in the operating room, and another $20 \%$ indicated that it occurred while working in an inpatient room.

Of interest is how the injury happened. $72 \%$ of those exposed indicated that it happened while they manipulated the sharp object in the patient. Most incidents occurred with syringes and butterflies during sample collection and line insertion.

\section{Discussion}

This study found that $21 \%$ of healthcare workers in this diagnostic center in the Dominican Republic experienced sharp object injuries. This study aims to set a benchmark to further improve healthcare workers' safety while improving patient safety in developing countries.

To reduce sharp exposures, certain measures should be taken. There are four main suggestions. Firstly, using the current information system, a sharps injury reporting system can be developed. The additional Injury Reporting (IR) module can have the following characteristics:

1. Track exposure,

2. Make informed improvements,

3. Monitor improvements,

4. Standardize safety processes

In the IR module, each healthcare worker has a login that brings them to a screen where they enter all exposures. Documenting an exposure using the proposed system can be done in a few minutes. The survey tool used to conduct this study can be used as a benchmark to develop the injury reporting screen. An alternate to this solution is using the Exposure Prevention Information Network (EPInet). EPInet contains a Sharps Injury reporting module that should be feasible to purchase. EPInet also provides their version of Needlestick and Sharp-Obejct Injury Report form. ${ }^{20}$ If 21 out 100 staff members require prophelaxis or some sort of care after the exposure, the hospital or institute will incur costs. These costs should decrease after a roll out of a comprehensive reporting system and program. The management of providing post exposure prophylaxis can be followed completely on the EPInet website titled Post Exposure Follow Up form. ${ }^{21}$

Secondly, a descriptive report should be generated monthly to assess the areas that are reporting the most sharps exposure. The report would be reviewed by the newly established Infection Control Committee. The committeewould beresponsibleforcarryingoutprojects to improve the monitoring and controlling of infectious agents throughout the hospital. The committee would also develop standards about how to treat an exposure to a sharp object. Education programs on sharp injuries have been shown to substantially decrease exposures for healthcare workers. ${ }^{22,}{ }^{23}$ Furthermore, the Infection Control Committee will need to address the safety issued posed by traditional syringes. Syringes are the single highest source of sharps exposure (26\%) and are also the sharp most commonly used in the facility. Purchasing needles with engineered safety controls can decrease the numbers of exposures as noted throughout this study. Vacutainers and blunt needles are common solutions that have been proven to be successful for this problem. 
Thirdly, additional prevention techniques can be integrated into the daily routines. In a study conducted by Gomma et. al, three improvement techniques to reduce sharp injuries and the introduction of "Hierarchy of Controls Prevention Model" are discussed. ${ }^{24}$ Under the "Hierarchy of Controls Prevention Model", the authors suggest the following 6 steps to reduce exposures:

1. Eliminate and reduce the use of needles and other sharps;

2. Isolate hazard by protecting exposed sharps through engineering control;

3. If 1 and 2 do not work, then use work-practice controls and personal protective equipment ;

4. Team approach to healthcare activity helps increase communication and improve outcomes

5. Prevention is the best approach to reduce sharps injuries

- Use neutral zone technique for passing of sharps between healthcare personnel

- Use of hands-free technique;

6. Increase focus on training

Finally, it is suggested that the surveys are retaken by staff every 6 months for a period of 2 years. This will validate the initial data captured in this study. Additionally, it will help Administration create and promote an environment of safety for their patients and workers.

\section{References}

1. 2007 EPINet Needlestick and Sharp Object Injury Report. http:// healthsystem.virginia.edu/internet/epinet/epinetdatareport. cfm\#report. Accessed on September 4, 2009.

2. Davis JR, Lederberg J. Public Health Systems and Emerging Infections: Assessing the Capabilities of the Public and Private Sectors: Workshop Summary (2000), Institute of Medicine

3. The Impact of Globalization on Infectious Disease Emergence and Control: Exploring the Consequences and Opportunities, Workshop Summary - Forum on Microbial Threats (2006), Board on Global Health

4. Center for Disease Control, Workbook for Designing, Implementing and Evaluating a Sharps Injury Prevention Program, revised 2008, Available at: www.cdc.gov/ sharpssafety/PPT/1WorkbookOverview.ppt

5. Danboy S. The Risk and Cost of Hepatitis B exposure in the Lab. Medical Laboratory Observer, 1984

6. Mehta, A, Rodrigues C, Ghag S, et al. Needlesticks injuries in a tertiary care centre in Mumbai. India J Hosp Infect 2005; 60: 368-373.

7. Holdisk, $\mathrm{CL}$, Barkauskas V. Reducing Percutaneous Injuries in the OR by Educational Method. AORN J 2000; 72(3): 461464, 468-472, 475-476.
8. National Institute of Occupational Safety and Health, NIOSH Alert: preventing needle stick injuries in healthcare settings, 1999, DHHS (NIOSH) publication No. 2000-108.

9. Kermode M. Unsafe injections in Low-Income Country health settings: need for injection safety promotion to prevent the spread of blood borne viruses, Health Promotion International 2005; 19(1): 95-103.

10. Kane A, Lloyd J, Zaffran M, et al. Transmission of Hepatitis B, Hepatitis $C$, and Human Immunodeficiency Viruses through unsafe injections in the developing world: model based regional estimate. Bull World Health Organ 1999; 77(10): 801-807.

11. Hauri AM, Armstrong GL, Hutin YJ. The global burden of disease attributable to contaminated injections given in health care settings. Int / STD AIDS 2004; 15(1): 7-16.

12. Tomkins S, Ncube F. Occupationally acquired HIV: international reports to December 2002. Euro Surveill 2005, 10: EO50310.2

13. Wikipedia, Available at: http://en.wikipedia.org/wiki/ Hepatitis_B

14. Center for Disease Control, Available at: http://www.cdc.gov/ ncidod/diseases/hepatitis/index.htm

15. Mazzur S, Nath N, Fang C, et al. Distribution of hepatitis B virus (HBV) in blood donors of 13 western hemisphere countries; proceedings of the red cross Latin American hepatitis B workshop. Bull Pan AmHealth Organ 1980; 14(1): 44-51.

16. Silveira TR, da Foseca JC, Rivera L, et al. Hepatitis B seroprevalence in Latin America. Pan Am / Public Health 1999; 6(6): 378-383.

17. http:// www.cdc.gov/sharpsafety/wk_overview.html

18. 2007 US EPINet Needlestick and Sharp Object Injury Report, Available at: http://healthsystem.virginia.edu/internet/epinet/ epinetdatareport.cfm\#report

19. Berguer R, Heller PJ. Strategies for Preventing Sharp Injuries in the Operating Room. Surg Clinics N Am 2005; 85: 12991305.

20. Needlestick and Sharp Object Injury Report Form, http://www. healthsystem.virginia.edu/internet/epinet/forms/epinet3.cfm

21. Post Exposure Follow Up form, http://www.healthsystem. virginia.edu/internet/epinet/forms/pef2001.pdf

22. Brusaferro S, Calligaris I, Farneti F, et al. Educational programmes and sharps injuries in healthcare workers. Occupational Medicine 2009; 59(7): 512-514.

23. RichardVS, Kenneth J, Ramaprabha, et al. Impact of introduction of Sharps containers and of educational programmes on the pattern of needlestick injuries in a tertiary care centre in India. J Hosp Infec 2001; 47: 163-165.

24. Gomaa A, Sincalir R, Alarcon W. Occupational Blood-Borne diseases in Surgery. The American Journal of Surgery 2006; 192(3): 408-410. 